\title{
Barbara Helwing, Patricia Rahemipour (eds.). Tehran 50. Ein halbes Jahrhundert deutsche Archäologen in Iran. Eine Ausstellung des Deutschen Archäologischen Instituts in Zusammenarbeit mit dem Museum für Islamische Kunst, Staatliche Museen Berlin
}

\section{Rémy Boucharlat}

\section{OpenEdition}

\section{Édition électronique}

URL : http://journals.openedition.org/abstractairanica/41168

DOI : 10.4000/abstractairanica.41168

ISSN : 1961-960X

Éditeur :

CNRS (UMR 7528 Mondes iraniens et indiens), Éditions de l'IFRI

Référence électronique

Rémy Boucharlat, « Barbara Helwing, Patricia Rahemipour (eds.). Tehran 50. Ein halbes Jahrhundert deutsche Archäologen in Iran. Eine Ausstellung des Deutschen Archäologischen Instituts in

Zusammenarbeit mit dem Museum für Islamische Kunst, Staatliche Museen Berlin », Abstracta Iranica [En ligne], Volume 34-35-36 | 2017, document 5, mis en ligne le 15 juillet 2016, consulté le 05 octobre 2020. URL : http://journals.openedition.org/abstractairanica/41168; DOI : https://doi.org/10.4000/ abstractairanica. 41168

Ce document a été généré automatiquement le 5 octobre 2020.

Tous droits réservés 


\title{
Barbara Helwing, Patricia
} Rahemipour (eds.). Tehran 50. Ein halbes Jahrhundert deutsche Archäologen in Iran. Eine Ausstellung des Deutschen Archäologischen Instituts in Zusammenarbeit mit dem Museum für Islamische Kunst, Staatliche Museen Berlin

\author{
Rémy Boucharlat
}

\section{RÉFÉRENCE}

Barbara Helwing, Patricia Rahemipour (eds.). Tehran 50. Ein halbes Jahrhundert deutsche Archäologen in Iran. Eine Ausstellung des Deutschen Archäologischen Instituts in Zusammenarbeit mit dem Museum für Islamische Kunst, Staatliche Museen Berlin. von Zabern, 2011, XVI-194 p., 202 ill. N\&B et coul. (Archäologie in Iran und Turan, 11)

L'Institut archéologique allemand, section Eurasie, dont la branche de Téhéran a été fondée en 1961, a fêté son 50e anniversaire. C'était l'occasion de présenter les activités des savants allemands pendant cette période mais en remontant plus loin dans le temps pour faire une part conséquente au grand Ernst Herzfeld. Les éditrices de ce livre et catalogue - BH étant l'auteure de la majorité des textes - ont rassemblé des archives très dispersées conservées à l'Institut de Téhéran, dans les musées de Berlin, à la Smithsonian Institution de Washington et au Metropolitan Museum of Art de New 
York; ces deux derniers conservent la majorité des archives de Herzfeld. Elles ont également sollicité les descendants d'acteurs importants comme le fils de F. Krefter, architecte des fouilles à Persépolis (1928-36) ou celui de W. Eilers.

Le résultat est un ensemble de documents très intéressants car, outre nombre des inédits, textes, photos, aquarelles, extraits de journaux, qui sont insérés dans tous les chapitres, chaque section est consacrée à une période, un thème ou un événement archéologique important. C'est l'occasion de porter un regard critique sur les personnes et les activités, toujours en relation avec la situation politique et culturelle du moment en Iran, que ce soit durant les deux guerres mondiales ou avec les règnes des deux Pahlavis.

3 La vie et l'œuvre de Herzfeld ont fait l'objet d'un important colloque publié en 2005, édité par A. C. Gunter \& S.R. Haudser (eds.) Ernst Herzfeld and the Development of the Near Eastern Studies, 1900-1950 ; pourtant il reste beaucoup de documents inédits, notes croquis et photos dont cet ouvrage donne quelques exemples (p. 37-73). On note également des textes et photos de visiteurs célèbres comme Robert Byron et Annemarie Schwarzenbach à Persépolis à l'époque de Herzfeld.

4 Les 50 ans d'activités de l'Institut de Téhéran forme la seconde partie du livre (p. 83-174). Dans la période de lancement de l'institution qui prit quelques années. Dans les premiers temps, une vision assez hellénocentriste de l'archéologie et de l'histoire de l'Iran prévalait à Berlin. Pour cette raison, et d'autres, les programmes marquèrent une préférence pour les périodes historiques. Avant même l'ouverture de l'institut, furent entreprises les très importantes fouilles de Taût-e Soleymān (1959-1975), centre dynastique des Sassanides profondément reconstruit au VI ${ }^{\mathrm{e}}$ s. de n.è., certainement l'un des sites les plus impressionnants d'Iran par sa situation autour d'un cratère rempli d'eau (qui n'est pas un volcan, mais une source artésienne), son architecture et son paysage. Des fouilles également sur le site voisin de Zendān-e Soleymān, sur un cône également, vide celui-là, d'époque "mède ", de 1959 à 1964, publiées rapidement. Les fouilles de Bīsotūn (1963-67) sont moins connues, moins spectaculaires sans doute ; elles devaient être publiées complètement en 1996 par W. Kleiss et P. Calmeyer. Puis, commencèrent les fouilles de Basțām, site urartéen en Azerbaijan occidental, sous la direction de W. Kleiss, de 1968 à 1978, publiées en deux volumes.

5 Les grandes fouilles allemandes, surtout dans la période de Die goldenen Siebziger, ont donc porté sur des sites d'époques historiques, en général avec une architecture importante. Il en est de même des travaux de D. Huff, à Firuzabad, avant tout une étude de surface, mais avec également des fouilles limitées sur le Qal'e DoHtar (1975-78) en vue de la préparation du programme de conservation et de restauration. Le même, spécialiste d'architecture, a parcouru certaines régions d'Iran en étudiant de petits monuments, tandis que $\mathrm{W}$. Kleiss dans ses longs périples relevait rapidement mosquées, châteaux, ponts anciens, et surtout caravansérails. Parallèlement, l'école des historiens d'art allemands s'intéressa à l'Iran ancien et médiéval. Au tout premier rang de ceux-ci, il faut citer, P. Calmeyer, dont les articles, très nombreux et toujours très approfondis, font toujours autorité.

6 Au lendemain de la Révolution, la recherche archéologique allemande a connu une période de relative inactivité puis a repris de manière encore limitée, sous la forme de missions conjointes. Le même processus vaut pour les institutions spécialisées des rares autres pays étrangers œuvrant en Iran. La recherche allemande a pris alors une toute autre orientation, délaissant les grands chantiers de sites historiques pour s'intéresser 
à la Pré- et Protohistoire, en intégrant les études paléo-environnementales, anthropobiologiques, etc. et en mettant en œuvre des techniques et méthodes modernes. En témoigne le programme d'étude sur les débuts de la métallurgie à Arisman (4 mill.), près de Kāšān (2000-2004), dont les cinq premières campagnes sont été publiées par A. Vatandust, H. Parzinger, B. Helwing (eds.), Early Mining and Metallurgie on the western Central Iranian Plateau, 2011. De même, lors des fouilles de sauvetage près de Pasargades (2005-2006), la principale mission irano-allemande a choisi de fouiller des sites des $5 \mathrm{e}$ et $4 \mathrm{e}$ millénaires, et une autre a étudié des traces de métallurgie sur des sites d'époque islamique. Les publications sont en cours.

7 Ces activités récentes, comme les anciennes, témoignent d'une qualité remarquable des recherches archéologiques allemandes - que n'avait pas Herzfeld dont les travaux à Persépolis sont restés inédits -, le suivi des recherches de terrain par des publications, souvent détaillées et dans des délais raisonnables que d'autres projets étrangers en Iran avant la Révolution peuvent leur envier.

\section{AUTEURS}

\section{RÉMY BOUCHARLAT}

CNRS, Lyon 